\title{
"MicroRNA expression profiling of human milk derived exosomes identifies miR-630 and miR-378g as biomarkers in HIV-1 infected women"
}

Muhammad Atif Zahoor ( $\square$ atif.zahoor@uhnresearch.ca )

University Health Network https://orcid.org/0000-0003-2302-3689

Xiao-Dan Yao

McMaster University Michael G DeGroote School of Medicine

Bethany M Henrick

Evolve Biosystems, Davis California

Chris $\mathrm{P}$ Verschoor

McMaster University Michael G DeGroote School of Medicine

Alash'le Abimiku

Institute of Human Virology

Sophia Osawe

Institue of Human Virology

Kenneth L Rosenthal

McMaster University Michael G DeGroote School of Medicine

Research article

Keywords: Human Milk, Exosomes, HIV-1, NanoString, microRNA, Biomarker, miR-378g, miR-630

Posted Date: March 9th, 2020

DOI: https://doi.org/10.21203/rs.3.rs-16324/v1

License: () (i) This work is licensed under a Creative Commons Attribution 4.0 International License. Read Full License 


\section{Abstract}

Background: Despite the use of antiretroviral therapy (ART) in HIV-1 infected mothers approximately $5 \%$ of new HIV-1 infections still occur in breastfed infants annually which warrant for the development of new additional strategies to completely prevent new HIV-1 infections in infants. Human Milk (HM) exosomes are highly enriched in maternal microRNAs (miRNAs) which after ingestion and absorption play an important role in neonatal immunity. Although, HM exosomes from healthy donors are known to inhibit HIV-1 transmission; the effect of HIV-1 on HM exosomal miRNA signatures remains unknown. In the present study, HM derived exosomal miRNA profiles were investigated in HIV-1 infected lactating women.

Methods: First week postpartum HM exosomes were purified from uninfected control and HIV-1 infected mothers $(n=36)$, processed for RNA extraction and subjected to miRNA expression profiling by NanoString technology. The data were analyzed, and targets were predicted.

Results: We describe that HIV-1 perturbed the differential expression pattern of 19 miRNAs (13 up and 6 downregulated) in HIV-1 infected women compared to healthy controls. DIANA-miR functional Pathway analyses revealed that multiple biological pathways are involved including Cell cycle, Pathways in Cancer, TGF- $\beta$ signaling, FoxO signaling, Fatty Acid Biosynthesis, p53 signaling and Apoptosis. Further, the receiver operating characteristics (ROC) curve analyses of two of the identified miRNAs, miR-630 and miR-378g for separating HIV-1 infected women from healthy controls yielded areas under the ROC curves of $0.82(95 \% \mathrm{Cl}=$ 0.67 to 0.82 ) and $0.83(95 \% \mathrm{Cl}=0.67$ to 0.83$)$, respectively highlighting their potential to serve as biomarkers of HIV-1 infection in women.

Conclusions: Our studies provide new information that HIV-1 perturbs the expression levels of HM derived exosomal miRNAs in lactating women. The stability of $\mathrm{HM}$ exosomes at room temperature raises the possibility of their utility in HIV-1 screening prior to HIV-1 specific testing in countries like Nigeria. Further, our data may also contribute to the development of new therapeutic strategies in prevention of mother-to-child transmission (MTCT) of HIV-1 in infants.

\section{Background}

With over 2.1 million new infections every year, approximately 40 million people are currently living with HIV1 worldwide [1]. It is estimated that more than 110,000 children die each year from HIV-1/AIDS related disorders and over 15,000 children are newly infected with HIV-1 every month [2]. Mother-to-child transmission (MTCT) of HIV-1 is an important source of HIV-1 infection in infants and can occur at any point including in utero, at the time of delivery and via breastfeeding. Although, use of maternal antiretroviral therapy (ART) reduces MTCT risk from 35\% without any intervention to less than $5 \%$, new HIV- 1 infection in infants who are breastfed by HIV-1 positive mothers remain an obstacle in preventing new infections. The World Health Organization (WHO) recommends that mothers known to be HIV-1 positive should exclusively breastfeed their infants for the first six months of life [2, 3], thus highlighting the need for the development of new intervention strategies in addition to available ART for the complete prevention of new HIV-1 infections in exclusively breastfed infants [4]. 
Most of the infants born to HIV-1 positive women do not become infected which is potentially attributed to the anti-HIV-1 molecules present in human milk $(\mathrm{HM})[5,6]$. It has been shown that HM exosomes but not the plasma derived exosomes, had a protective effect and inhibit HIV-1 infection of monocyte derived dendritic cells (MDDCs) and subsequent transfer to CD4 + T-cells. Thus, it has been suggested that HM derived exosomes reduce the risk of MTCT of HIV-1 through breastfeeding [7]. Exosomes are nanosized intraluminal extracellular vesicles secreted by a variety of cells that are present in almost all biological fluids. They are specialized in long distance intracellular communication and facilitating the transfer of nucleic acids such as mRNAs and microRNAs (miRNAs) for subsequent expression in target cells in a highly regulated and efficient manner [8, 9]. miRNAs are small, single-stranded, non-coding endogenous RNAs which suppresses the target gene expression through translational repression [10-12]. miRNAs play a key role in diverse biological processes including proliferation, differentiation and apoptosis [13]. Since miRNAs exist in plasma, urine, milk and other body fluids [14], these hold a great promise to serve as useful biomarkers in various diseases including cancer [15-17].

Identification of HM exosomal miRNAs could be critical and play an important role in HIV-1 infection during MTCT. However, no such study exists which can document the expression profile of HM exosomes from HIV1 infected women. Here, we investigated the expression profile of HIV-1 associated miRNAs in HM samples collected from HIV-1 infected women. As a result, we identified a total of 19 miRNAs (fold change >1.3; $p<$ 0.05 ) which were differentially expressed in women infected with HIV-1 and targeted the cellular genes that are involved in multiple biological pathways such as Cell Cycle, Pathways in Cancer, Viral Carcinogenesis, Adherens Junctions, TGF- $\beta$ signaling, Fatty Acid Biosynthesis, p53 signaling and Apoptosis. Further, we showed that a combination of two miRNAs, miR-630 and miR-378 g could serve as biomarkers of HIV-1 in discerning HIV-1 infected women from healthy controls. Taken together, we have unraveled the HM exosomal miRNAs which could be exploited in future studies for monitoring HIV-1 status in infected mothers as well as their potential role in the prevention of MTCT in infants.

\section{Methods}

\section{Human subjects}

HIV-1-uninfected healthy control and HIV-1-infected women were recruited from the Plateau State, Nigeria to participate in the current study. All women were sampled during their voluntary 'healthy' research visits as per the cohort protocol [18], and therefore, were not acutely ill at the time of sample collection. Women who were included in the study, were not taking medications other than ART or vitamin supplements intra- or postpartum and did not receive an epidural intra-partum. In addition, women were excluded if they had caesarean sections or they were diagnosed with mastitis post-partum.

\section{Sample acquisition and preparation}

HM samples were self-collected into sterile tubes within the first week and at one, three, and six months postpartum, and immediately shipped on ice for processing in our laboratory. The samples were separated into lipid, skim milk supernatant, and cellular fractions and stored at $-80^{\circ} \mathrm{C}$ and liquid nitrogen, respectively as previously described $[19,20]$. 


\section{Exosome isolation from human milk}

Exosomes were isolated from the skim milk supernatants using the Total Exosomes Isolation reagent (from other body fluids) as per manufacturer's recommendations (Thermo Fisher, Canada). Briefly, 500ul volume of each HM sample was centrifuged at $2000 \mathrm{xg}$ for 10 minutes ( $\left.1^{\text {st }} \mathrm{spin}\right)$. Without disrupting the pellet, supernatant was transferred to a new tube and centrifuged again at $10,000 \times \mathrm{g}$ for 30 minutes ( $2^{\text {nd }}$ spin). The supernatant was transferred to a new tube and centrifuged at $10,000 \times \mathrm{g}$ for 10 minutes ( $3^{\text {rd }} \mathrm{spin}$ ). To the clear supernatant, $500 \mu \mathrm{l}$ of 1 xPBS and $500 \mu \mathrm{l}$ of exosome isolation reagent was added, vortex-mixed and incubated for 30 minutes at room temperature. After, incubation, the samples were centrifuged at 10,000 x g for 10 minutes and the supernatant was removed carefully and discarded. The exosomes in the pellets were dissolved in 50 $\mathrm{\mu l}$ of exosome resuspension buffer (Thermo Fisher, Canada), vortex-mixed and again centrifuged at $10,000 \times \mathrm{g}$ for 5 minutes at room temperature. Without disturbing the non-organic particulate matter in the pellet, the supernatants containing the purified HM exosomes were transferred to a new tube and stored at $-20^{\circ} \mathrm{C}$ until further use.

\section{Transmission Electron Microscopy (TEM)}

HM derived exosomes morphology was evaluated by TEM through negative staining as described [21]. Briefly, HM exosomes were placed onto formvar grids, fixed with $2.5 \%$ glutaraldehyde and contrasted with $1 \%$ uranyl acetate and finally visualized with a JOEL-1200EX transmission electron microscope located at McMaster Electron Microscopy facility. The images with 40,000-300,000X magnifications were taken using AMTV600 computer program.

\section{Western Blotting}

Exosomes were isolated from the HM samples as described above. Protein fraction was isolated, quantified using DC ${ }^{\mathrm{TM}}$ protein assay kit (Bio-Rad) and run on SDS-PAGE gel. Western blot analysis was performed with the primary antibody against CD81 (sc-166029; Santa Cruz) and HRP-labeled goat anti-mouse IgG 1706516 (Bio-Rad) as secondary antibody as described $[19,20]$.

\section{Exosome RNA isolation}

Total RNA was extracted from the HM exosomes using Total Exosome RNA and Protein Isolation Kit as per manufacturer's instructions (Invitrogen, Carlsbad, CA). Briefly, the isolated exosomes were dissolved in prewarm $2 X$ denaturing solution followed by acid-phenol: chloroform extraction. The upper aqueous phase was precipitated with ethanol and total RNA was eluted with preheated $\left(95^{\circ} \mathrm{C}\right)$ elution buffer. The concentration of RNA was determined using the Nanodrop spectrophotometer (Nanodrop Technologies, Inc, Wilmington, Germany) as described [22] and were stored at $-80^{\circ} \mathrm{C}$ until further use.

\section{NanoString nCounter miRNA profiling and data analysis}

Before processing of the NanoString chip, RNA samples were analyzed with the Agilent Bioanalyzer 2100 and the RNA 6000 Nano LabChip Kit (Agilent, CA, USA). Exosomal miRNA expression profiling was performed using the nCounter Human ver 3.0 miRNA Panel on nCounter Analysis System (NanoString 
Technologies) as described [23]. For data analysis, raw NanoString counts were pre-processed and differential counts derived using the R package 'edgeR' (PMID: 19910308) as described [22]. Briefly, counts were normalized using trimmed mean of M-values (TMM) method and miRNA that were less than the geometric mean of negative control probes for more than half of the samples were removed; the final miRNA count for differential expression analysis was 267. Differential expression between groups was calculated using the function exactTest, which is analogous to Fisher's exact test, but adapted for overdispersed data (PMID: 19910308). Adjusted p-values were derived using Benjamini-Hochberg's procedure for controlling false discovery rate. In order to predict the role of these miRNAs as a biomarker, Receiver Operating Characteristic (ROC) curves were generated for the top five miRNAs and their areas under the curve (AUC) were calculated using the R package "plotROC" ( $p<0.001)$.

\section{In-Silico bioinformatic analysis}

For functional classification of miRNAs, DIANA-mirPath v3.0 was used for Kyoto Encyclopedia of Genes and Genomes (KEGG) pathway and Gene Ontology (GO) annotation analyses as described [24]. DIANA-Tarbase and "Pathways Union" options were selected to perform a KEGG pathway analysis using this database of experimentally validated targets. For $\mathrm{GO}$ analysis, miRNAs belonging to specific $\mathrm{GO}$ categories based on the experimental findings with "Categories Union" was conducted. The significance of each functional annotation term was generated using a modified Fisher's exact test with $p$-value threshold of $<0.05$ for KEGG pathways and $<1 \mathrm{e}-20$ for GO analysis, respectively as described [24]. The candidate target genes of the identified miRNAs were predicted using TarBase v8.0 [25]. The untranslated region (UTR) location was predicted by TargetScan v7.2 [26]. In order to identify the potential interactions of the differentially expressed miRNAs in HM from HIV-1 infected women, miRNA-mRNA Network analysis was performed using Network Analyst software [22] where miRNA to gene interaction data were collected from well-annotated databases such as miRTarBase v7.0, TarBase v7.0 and miRecords as described [27]. For degree, betweenness and shortest Path, "All but miRNA nodes" filter option was selected for the analysis.

\section{Results}

\section{Clinical characteristics of women participants}

HM derived exosomes were isolated from both HIV-1 infected and uninfected control women and processed for miRNA profiling. A schematic illustration of the study layout is shown in Figure 1. In this study cohort, both HIV-1 infected and uninfected women were recruited from the Plateau State, Nigeria as described [20, 28]. Although, a series of HM samples were collected and shipped to Canada, a total of $36 \mathrm{HM}$ samples from the first week postpartum (27 HIV-1 positive and 9 HIV-1 negative as controls) were processed for HM exosome miRNA profiling. The details of the women (average age 31 years) who participated in the study are shown in Table 1 which revealed that out of 27 HIV-1 positive women, 22 were carrying HIV-1 for 4 15 years whereas 5 women were carrying HIV-1 for only 3 years. Further, all HIV-1 positive women were on ART (CD4+ count $\leq 300 / \mathrm{mm}^{3}$ with undetectable viral load) and receiving antiretroviral drugs according to the regimen set by Nigerian Government and the WHO as described [29]. It was impossible to obtain samples from ARTnaïve HIV-1 positive women. Number of years on ART were counted, the day a woman was diagnosed 
positive for HIV-1 and placed on ART. As shown in Table 1, 13 out of 22 HIV-1 positive women showed high infant mortality compared to the control women whereas 5 HIV-1 positive women never had experienced any pregnancy. In addition, upon follow-up infants born to these HIV-1 positive women were found stunted and underweight as described [18].

\section{Milk exosome characterization and RNA quality check}

HM samples were processed for exosome isolation and confirmed by TEM. A representative image of HM exosomes is shown in Figure 2A which revealed that HM derived exosomes are $30-100 \mathrm{~nm}$ in size and are largely spherical in shape. For further confirmation of exosomes, a Western blot analysis was performed using an exosome protein marker CD81. Different concentrations of exosome proteins extracted from either freshly isolated or exosomes kept at room temperature for two days were loaded which confirmed the presence and stability of exosomes in HM (Figure 2B). Next, exosomes were processed for RNA isolation. RNAs were isolated from all HIV-1 positive and negative HM samples with an average yield of $40 \mathrm{ng} / \mu \mathrm{l}$ as quantified by Nanodrop spectrophotometer. The isolated total RNAs showed spikes distinctive of noncoding RNA bands at $>25$ nucleotides using as Agilent 2100 Bioanalyzer (Figure 2C \& 2D). RNA samples which did not pass the quality check were excluded and replaced with new RNA samples, thus, only high quality RNAs were processed for miRNA NanoString profiling.

\section{Identification of HM derived exosomal miRNAs from HIV-1 infected women}

Differentially expressed exosomal miRNAs from HM samples obtained from both HIV-1 positive and negative women were profiled using the Human nCounter miRNA ver 3.0 which interrogates 800 human miRNAs (NanoString). A total of three cartridge chips were run at the same time each consisting of 12 samples ( 9 HIV-1 positive and 3 negative control per chip). Differentially expressed miRNAs were identified between HIV-1 positive and negative control women using log base 2-fold change (FC) of the levels of miRNAs between HIV-1 positive group and non-HIV-1 control group. A volcano plot showing miRNAs with altered expression in HIV-1 infected HM samples is shown in Figure 3. A total of 41 miRNAs were found to be significant $(p<0.05)$ in HIV-1 positive women compared to control women. A complete list of all 41 miRNAs is shown in Suppl Table 1. As shown in Table 2, out of 19 miRNAs, which were differentially regulated ( $p$ $<0.05$; FC >1.3), 13 were found upregulated (hsa-miR-320e; hsa-miR-630; hsa-miR-148a-3p; hsa-miR-23a-3p; hsa-miR-378g; hsa-miR-30a-5p; hsa-miR-93-5p; hsa-miR-497-5p; hsa-miR-200b-3p; hsa-miR-200a-3p; hsa-miR16-5p; hsa-miR-1262 and hsa-miR-4516) and 6 were found downregulated (hsa-miR-422a; hsa-miR-644a; hsa-miR-520a-5p; hsa-miR-506-5p; hsa-miR-1257 and hsa-miR-1253). From hereon, the prefix hsa was removed from the miRNAs.

\section{Top ten miRNAs and their potential target genes}

Since miRNAs act by directly silencing and reducing the expression of their target genes, we next predicted the potential targets of the top ten differentially expressed miRNAs using Tarbase v8.0 which produces a list of validated target genes [25]. As a result, we obtained a total of 19895 interactions. Some of the target genes are shown in Table 3. miR-16-5p was found to target the largest number of genes including IRF9, TLR4, TLR6, JUN followed by miR-30a-5p, miR-93-5p and miR-200b-3p (Table 3). miR-630 was shown to 
target BCL2, BCL2L11 and YAP1. miR-378g was shown to target 123 genes including SMAD2, CREBBP, WDR5 etc. Interestingly, multiple miRNAs were found to be involved in targeting a single mRNA gene such as BCL2L11 that was a target of miR-320e and miR-148a-3p. BCL2L2 was a target of miR-630 and miR-497-5p. NOTCH1 was a target of miR-30a-5p and miR-200b-3p. SMAD2 was a target of miR-378g, miR-497-5p and miR-16-5p (Table 3).

\section{GO and KEGG pathways}

KEGG pathway analysis on the predicted targets using DIANA-mirPath v 3.0 led to the identification of 31 significant KEGG pathways in which the predicted miRNA targets were enriched (Figure 4). A heatmap was generated from DIANA-miRPath v3.0, which shows miRNA targets associated with HIV-1 and belonged to multiple pathways such as Pathways in Cancer, Viral carcinogenesis, Adherens Junctions, TGF- $\beta$, Fatty acid Biosynthesis, p53 signaling, Cell Cycle, Pathways regulating pluripotency of stem cells, Proteoglycans in Cancer etc (Figure 4). Next, we performed GO analysis to identify the biological processes associated with the miRNAs. A total of $30 \mathrm{GO}$ biological processes were observed (Figure 5). The highest enrichment GO terms targeted by these miRNAs included Biosynthetic Process followed by Viral process, Catabolic process, Cell death, lon binding, Membrane organization, Mitotic cell cycle, RNA metabolic process, poly (A) RNA binding, Neurotropin TRK receptor signaling pathway etc (Fig 5).

\section{miRNA-Gene interaction network}

To understand the association of differentially expressed miRNAs in HIV-1 infected HM and their target proteins, miRNA-gene interaction network was generated using miRNet tool. The 19 differentially expressed miRNAs were uploaded into miRNet platform and miRNA-gene interactions were observed which generated 4190 target nodes and 6042 edges. Shortest Path filter with "All but miRNA nodes" generated 124 nodes with 105 targets and 393 edges (Figure 6). The top cluster hubs were miR-16-5p followed by miR-497, miR-93-5p, miR-30a-5p and miR-23a-5p. The biological functions were determined within the "reactome database" using the "hypergeometric test" algorithm and $p$-value $<0.05$. Results showed that Pre-Notch transcription and translation (TP53, E2F3, AG02, CCND1) was the top group followed by Mitotic G1/S phase (Wee1, CDK6, CDKN1A, E2F3, PSMD11, CCND1, CCNE2), Cyclin D associated events in G1 (E2F3, CDK6, CDKN1A, CCND1), EGFR signaling (EGFR, GRB2, HSP90AA1), Intrinsic pathway of apoptosis (BCL2, XIAP, TP53, DYNLL2) and Cell cycle (BIRC5, CCND1, CDK6, CDKN1A, CCNE2, WEE1, TP53, PSMD11, PAFAH1B1, HSP90AA1, E2F3, TAOK1, FOXM1, CSNK2A1). Collectively, these results demonstrate that the target genes of miRNAs perturbed by HIV-1 belong to multiple biological pathways.

\section{ROC curves}

In order to evaluate the utility of exosomal miRNAs in HM, we performed ROC curve analysis of top 5 miRNAs in discriminating HIV-1 infected women from healthy controls which showed that miR-320e, miR148a-3p, miR-378g, miR-630 and miR-23a-3p have ROC AUC values of 0.75 ( $95 \% \mathrm{Cl}=0.58$ to 0.75 ), 0.79 ( $95 \% \mathrm{Cl}=0.6$ to 0.75$), 0.83(95 \% \mathrm{Cl}=0.67$ to 0.83$), 0.82$ ( $95 \% \mathrm{Cl}=0.67$ to 0.82 ) and 0.72 ( $95 \% \mathrm{Cl}=0.55$ to 0.72 ) respectively (Figure 7). Further, when miR-630 and miR-378g were combined, it yielded ROC AUC of 
0.86 (95\% $\mathrm{Cl}=0.72$ to 0.86 ) (Figure 7 ) thus suggesting that miR-630 and miR-378g could serve as biomarkers to distinguish HIV-1 infected women from healthy controls and could accurately discern HIV-1 from control.

\section{Hypothetical model showing miR-378g mediated HIV-1 transactivator (TAR) binding protein 2 (TARBP2) depletion and its predicted role in HIV-1 infection}

TargetScan predicts the targets of miRNAs by searching for the presence of conserved 8-mer, 7-mer and 6mer sites that match the seed regions of each mRNA [13]. TargetScan ver 7.2 database was utilized to predict and identify the target genes of miR-378g. In order to identify which of these potential targets are relevant to HIV-1, TargetScan results were interrogated with the search term HIV. Results showed that miR$378 \mathrm{~g}$ has one target site in 3'UTR of TARBP2 (ENST 00000552857.1) from 382-388 (Figure 8A). TARBP2 is known to promote HIV-1 LTR expression and viral production whereas its siRNA-mediated knockdown inhibits HIV-1 LTR expression and viral production [30]. A schematic of the hypothetical layout is shown in Figure 8B, where we speculate that miR-378g mediated RNA interference would lower HIV-1 expression and viral production essentially as previously described [31].

\section{Discussion}

HIV-1 is known to cause dramatic changes in cellular miRNA expression profiles [32-35], however its effect on HM derived exosomal miRNAs remains to be determined. Here, we first demonstrate the miRNA expression profiling of HM derived exosomes from HIV-1 infected women and describe that HIV-1 significantly altered the expression levels of HM derived exosomal miRNAs in HIV-1 infected women. Analysis of differentially expressed miRNAs by a gene ontology and KEGG pathway-based approach revealed that several biological processes are affected by HIV-1. Finally, we identified two dysregulated miRNAs that can potentially discriminate HIV-1 positive women from healthy controls, with good predictive power. Collectively, our data provide the first comprehensive insight into HM exosomal miRNA profiles involved during HIV-1 infection.

Exosomes have recently emerged as new players in HIV-1 infection albeit their exact role in HIV-1 pathogenesis and transmission is not clear [34]. Exosomes may act at different levels of HIV-1 pathogenesis by modulating immune responses, infectivity or even activating the latent viral reservoirs [9]. The impact of exosomes on HIV-1 has been suggested for better HIV-1 cure and control strategies [36]. Only few reports exist which demonstrate that HM derived exosomes possess immune-modulatory functions [37] that partly could be due to the methodological limitations in their isolation and purification [8]. In this study, we have provided a successful HM exosome isolation method that will aid in future studies related to HM derived exosome isolation and characterization.

To gain more insight into HM derived exosomal miRNAs modulation by HIV-1, we performed NanoString miRNA profiling and showed that HIV-1 perturbed the expression levels of 19 miRNAs $(F C>1.3 ; p<0.05$; Table 2). Further, we identified 31 KEGG pathways potentially regulated by miRNAs that mainly included Pathways in Cancer, TGF- $\beta$, Fatty acid Biosynthesis, FoxO signaling, p53 signaling, Cell Cycle, Pathways regulating pluripotency of stem cells, Proteoglycans in Cancer etc (Fig. 4). miRNA-mRNA network showed that the differentially expressed miRNAs are linked to each other via their target genes (Fig. 6). miRNA-mRNA 
network analysis, in addition to cell cycle, apoptosis identified the involvement of NOTCH and EGFR pathways.

A combination of two miRNAs (miR-630 and miR-378 g) had $86 \%$ accuracy rate of predicting HIV- 1 disease (Fig. 7) and may serve as a biomarker for segregating HIV-1 positive women from uninfected controls. The stability of HM exosomes at room temperature also raises the possibility of their utility in initial screening processes prior to HIV-1 specific blood testing in countries like Nigeria. Further, majority of the women who participated in the study were carrying HIV-1 viral load for $>5$ years (Table 1), thus it is suggested these two miRNAs could be used to monitor AIDS progression in HIV-1 infected women. Our finding is in agreement with a previous study where miR-630 was reported as a biomarker in chronic progressors of HIV-1 [38]. Interestingly, our HM exosomal miRNA data from the South Africa cohort where HIV-1 infected women were carrying HIV-1 load $<1$ year (data not shown) showed downregulation of these miRNAs identified in the current study (Table $2 \&$ Suppl Table 1) and correlated with a recent report where it was shown that acute HIV-1 leads to downregulation of miRNAs [32]. Nonetheless, miRNA data shown herein could be exploited for future studies to gain more insight into HIV-1 pathogenesis.

miRNAs are thought to be involved in mediating immune suppression, establishment of viral latency $[34,39]$ or suppress HIV-1 replication via decreasing HIV-1 dependency factors [40]. Some of the miRNAs we have identified have been previously implicated in HIV-1 infection including miR-630, miR-4516, miR-16-5p, miR378 , miR-93, miR-23, miR-30a [32, 38, 41-44] thus strongly suggesting the reliability of the NanoString data obtained in the current study. Further, it has been described that NanoString can perform miRNA profiling with digital precision and the results do not require further validation by another method [45]. miRNA-630 causes apoptosis by targeting BCL2, BCL2L2 and IGF-1R [46] or maintains the apoptotic balance by targeting multiple modulators [47]. miR-15a/b, miR-16, miR-20a, miR-93, miR-106b have been shown bind to Pur- $a$ and repress its expression [43]. Pur- $a$ is a cellular partner for Tat regulatory protein of HIV-1 and facilitates its transcriptional activity $[48,49]$ and is required for HIV-1 infection in macrophages $[43,50]$. We found that Pur- $\alpha$ is a target of HM exosomal miR-93-5p and miR-497-5p (Table 3). Whether HM exosomal miR-93-5p and miR-497-5p lower the R5-tropic HIV-1 infection of macrophages is not known but will be intriguing to investigate in future studies.

HM derived immunomodulatory factors are transferred from mothers to infants via breastmilk which include immunoglobulins, cytokines, chemokines, growth factors, hormones, lactoferrins and Toll-like receptors [19, 20, 51-55]. TGF- $\beta$ is a major cytokine in HM which favors preferential MTCT of R5-tropic HIV-1 [56, 57]. miR$378 \mathrm{~g}$, miR-16-5p and miR-497-5p were found to target SMAD2 (Table 3 ) which is known to mediate TGF- $\beta$ and regulate multiple pathways such as cell proliferation, apoptosis and cellular differentiation [56, 58]. HIV1 positive human skim milk fraction after heat inactivation and proteolytic digestion retains HIV-1 inhibitory activity and was shown to significantly inhibit oral HIV-1 transmission in-vivo [3]. Since, HM exosomal miRNAs are known to reach the systemic circulation [37], it implies that the HM derived exosome containing miRNAs reported herein reach the fetal systemic circulation via breastmilk and play an important role in lowering MTCT of HIV-1 [7]. Further future studies are required to elucidate the functional role of these HM exosomal miRNAs. 
Using a consensus scoring approach, it has been shown that miR-378 targets HIV-1 envelope gene [42]. mir378 family consist of 11 mature miRNA members according to miRbase database (www.mirbase.org) comprising of miR-378a-5p, miR-378a-3p, miR-378b, miR-378c, miR-378d, miR-378e, miR-378f, miR-378 g, miR-378 h, miR-378i and miR-378j. Our studies are the first showing the involvement of miR-378 $\mathrm{g}$ in HIV-1 infection. Further, target prediction analysis suggested that miRNA-378 $\mathrm{g}$ targets a site located in $3^{\prime} \mathrm{UTR}$ of TARBP2 from 382-388 nucleotides (Fig. 8), which is required by HIV-1 for its expression and virion production $[30,59]$. Interestingly, astrocytes are shown to be resistant to HIV-1 infection due to low endogenous levels of TARBP2 [60]. TARBP2 was originally identified as a protein that binds to the 59 nucleotides conserved TAR element found at the $5^{\prime}$ and $3^{\prime}$ ends of all HIV- 1 transcripts and enhances its translation and replication [31, 59, 61]. In addition, miR-378 $\mathrm{g}$ was also found to target 4 confidently annotated sites in 3'UTR of human HIV-1 enhancer binding protein 3 (HIVEP3) (ENST00000372583.1) located at 582-588, 2026-2032, 2208-2214 and 2580-2586 nucleotides (data not shown). Although, role of HIVEP3 in HIV-1 replication is not clear, targeting HIVEP2 by miRNAs is known to reduce HIV-1 replication [62]. The effect of miR-378 $\mathrm{g}$ on HIV-1 replication and MTCT must be investigated in future studies.

HIV-1 associated neurologic disease (HAND) occurs in more than $25 \%$ of HIV- 1 infected patients who develop AIDS with disease progression [63]. Previously, miR-4516 has been shown to be a biomarker of HAND in HIV-1 infected patients [41]. Our data showed that miR-4516 is upregulated in HIV-1 infected women (Table 2). Whether these HIV-1 infected women were HAND-asymptomatic or already had developed HAND is not known since our clinical data did not reveal any neurologic symptoms in these infected women. It will be interesting to monitor the immune status as well as the temporal expression pattern of miR-4516 in future studies.

\section{Conclusions}

We are the first to demonstrate the expression profiling of HM exosomal miRNAs in HIV-1 infected women. Use of current ART in HIV-1 positive mothers fails to completely stop MTCT of HIV-1, interventions in addition to available ART are required in order to prevent new infections of HIV-1 in infants. In this context, our data with new details on miRNAs present in HM exosomes could be exploited to lower HIV-1 infection through MTCT. Further, the miRNAs reported herein may serve as potential biomarkers of HIV- 1 in infected mothers.

\section{Abbreviations}

AIDS

Acquired immunodeficiency syndrome; ART:antiretroviral therapy; AUC:area under curve; HIV-1:Human immunodeficiency virus 1; HM:human milk; KEGG:Kyoto encyclopedia of genes and genomes; LTR:long terminal repeat; MDDCs:monocyte derived dendritic cells; miRNAs:microRNAs; MTCT:mother-to-child transmission; ROC:receiver operating characteristics; TEM:transmission electron microscopy; UTR:untranslated region; WHO:world health organization

\section{Declarations}




\section{Ethics approval and consent to participate}

Written as well as informed consent for the collection of demographics, behavioral data, and biological samples were obtained from all study participants. The study was approved by the McMaster Research Ethics Board (REB Approval \#08-176), CCl of Children's Hospital, Los Angeles, the institutional review boards of the University of Manitoba Hospital ethical review committee, University of Maryland Baltimore and Plateau State Specialist Hospital Nigeria Institutional Review Boards as described previously [18, 20] . All clinical investigations were conducted according to the principles of the Helsinki Declaration.

\section{Consent for publication}

Not applicable

\section{Author's contributions}

All authors have read and approved the manuscript. $\mathrm{MZ}, \mathrm{XD}$ and $\mathrm{BH}$ performed the experiments. $\mathrm{MZ}$ and $\mathrm{CP}$ performed the data analysis. AA and SO performed clinical studies and collected the human samples. MZ and KR wrote the manuscript. KR conceived the idea, obtained the grant and supervised the work.

\section{Competing interests}

$\mathrm{BH}$ is an employee of Evolve Biosystems. All other authors declare no competing interests.

\section{Availability of data}

The datasets reported and analyzed in the current study are available in NCBI Gene Expression Omnibus (GEO) repository and are accessible through GEO series accession number GSE143039.

\section{Acknowledgments}

We are grateful to Christine King and Marcia Reid of the McMaster University for providing invaluable help with NanoString analysis and electron microscopy, respectively. We would like to thank the Nigerian women who participated in our study.

\section{Funding}

This work was supported by a grant from the Canadian Institutes of Health Research (ClHR) as a part of the Canadian HIV-1 Vaccine Initiative (CHVI). 


\section{References}

1. UNAIDS. Fact sheet - Latest global and regional statistics on the status of the AIDS epidemic. UNAIDS Fact Sheet 2017. 2017.

2. WHO. WHO | HIV/AIDS. WHO. 2016.

3. Wahl A, Baker C, Spagnuolo R, Stamper L, Fouda G, Permar S, et al. Breast milk of HIV-positive mothers has potent and species-specific in vivo HIV-inhibitory activity. J Virol. 2015.

4. Bulterys M, Fowler MG, Van Rompay KK, Kourtis AP. Prevention of Mother-to-Child Transmission of HIV1 through Breast-Feeding: Past, Present, and Future. J Infect Dis. 2004.

5. Palma P. Human breast milk: is it the best milk to prevent HIV transmission? J virus Erad. 2016.

6. Van De Perre P, Rubbo PA, Viljoen J, Nagot N, Tylleskär T, Lepage P, et al. HIV-1 reservoirs in breast milk and challenges to elimination of breast-feeding transmission of HIV-1. Science Translational Medicine. 2012.

7. Näslund TI, Paquin-Proulx D, Paredes PT, Vallhov H, Sandberg JK, Gabrielsson S. Exosomes from breast milk inhibit HIV-1 infection of dendritic cells and subsequent viral transfer to CD4+ T cells. AIDS. 2014.

8. Ellwanger JH, Veit TD, Chies JAB. Exosomes in HIV infection: A review and critical look. Infection, Genetics and Evolution. 2017.

9. Madison MN, Okeoma CM. Exosomes: Implications in HIV-1 pathogenesis. Viruses. 2015.

10. Guo H, Ingolia NT, Weissman JS, Bartel DP. Mammalian microRNAs predominantly act to decrease target mRNA levels. Nature. 2010.

11. Winter J, Jung S, Keller S, Gregory RI, Diederichs S. Many roads to maturity: MicroRNA biogenesis pathways and their regulation. Nature Cell Biology. 2009.

12. Selbach M, Schwanhäusser B, Thierfelder N, Fang Z, Khanin R, Rajewsky N. Widespread changes in protein synthesis induced by microRNAs. Nature. 2008.

13. Lewis BP, Shih IH, Jones-Rhoades MW, Bartel DP, Burge CB. Prediction of Mammalian MicroRNA Targets. Cell. 2003.

14. Weber JA, Baxter DH, Zhang S, Huang DY, Huang KH, Lee MJ, et al. The microRNA spectrum in 12 body fluids. Clin Chem. 2010.

15. Verma P, Pandey RK, Prajapati P, Prajapati VK. Circulating microRNAs: Potential and emerging biomarkers for diagnosis of human infectious diseases. Frontiers in Microbiology. 2016.

16. Wang J, Chen J, Sen S. MicroRNA as Biomarkers and Diagnostics. Journal of Cellular Physiology. 2016.

17. Correia CN, Nalpas NC, McLoughlin KE, Browne JA, Gordon S V., MacHugh DE, et al. Circulating microRNAs as potential biomarkers of infectious disease. Frontiers in Immunology. 2017.

18. Jumare J, Datong P, Osawe S, Okolo F, Mohammed S, Inyang B, et al. Compromised Growth Among HIVexposed Uninfected Compared With Unexposed Children in Nigeria. Pediatr Infect Dis J. 2019.

19. Henrick BM, Yao XD, Rosenthal KL. HIV-1 structural proteins serve as PAMPs for TLR2 heterodimers significantly increasing infection and innate immune activation. Front Immunol. 2015. 
20. Henrick BM, Yao XD, Zahoor MA, Abimiku A, Osawe S, Rosenthal KL. TLR10 Senses HIV-1 Proteins and Significantly Enhances HIV-1 Infection. Front Immunol. 2019.

21. Zahoor MA, Philip S, Zhi H, Giam C-Z. NF- B Inhibition Facilitates the Establishment of Cell Lines That Chronically Produce Human T-Lymphotropic Virus Type 1 Viral Particles. J Virol. 2014.

22. Zahoor MA, Woods MW, Dizzell S, Nazli A, Mueller KMKM, Nguyen PVP V., et al. Transcriptional profiling of primary endometrial epithelial cells following acute HIV-1 exposure reveals gene signatures related to innate immunity. Am J Reprod Immunol. 2018;79.

23. Foye C, Yan IK, David W, Shukla N, Habboush Y, Chase L, et al. Comparison of miRNA quantitation by Nanostring in serum and plasma samples. PLoS One. 2017.

24. Vlachos IS, Zagganas K, Paraskevopoulou MD, Georgakilas G, Karagkouni D, Vergoulis T, et al. DIANAmiRPath v3.0: Deciphering microRNA function with experimental support. Nucleic Acids Res. 2015.

25. Karagkouni D, Paraskevopoulou MD, Chatzopoulos S, Vlachos IS, Tastsoglou S, Kanellos I, et al. DIANATarBase v8: A decade-long collection of experimentally supported miRNA-gene interactions. Nucleic Acids Res. 2018.

26. Agarwal V, Bell GW, Nam J-W, Bartel DP. Predicting effective microRNA target sites in mammalian mRNAs. Elife. 2015.

27. Fan Y, Siklenka K, Arora SK, Ribeiro P, Kimmins S, Xia J. miRNet - dissecting miRNA-target interactions and functional associations through network-based visual analysis. Nucleic Acids Res. 2016.

28. Henrick BM, Yao XD, Taha AY, Bruce German J, Rosenthal KL. Insights into soluble Toll-like receptor 2 as a downregulator of virally induced inflammation. Frontiers in Immunology. 2016.

29. Dalhatu I, Onotu D, Odafe S, Abiri O, Debem H, Agolory S, et al. Outcomes of Nigeria's HIV/AIDS treatment program for patients initiated on antiretroviral treatment between 2004-2012. PLoS One. 2016.

30. Christensen HS, Daher A, Soye KJ, Frankel LB, Alexander MR, Laine S, et al. Small interfering RNAs against the TAR RNA binding protein, TRBP, a Dicer cofactor, inhibit human immunodeficiency virus type 1 long terminal repeat expression and viral production. J Virol. 2007.

31. Bannwarth S, Gatignol A. HIV-1 TAR RNA: The Target of Molecular Interactions Between the Virus and its Host. Curr HIV Res. 2005.

32. Lodge R, Ferreira Barbosa JA, Lombard-Vadnais F, Gilmore JC, Deshiere A, Gosselin A, et al. Host MicroRNAs-221 and -222 Inhibit HIV-1 Entry in Macrophages by Targeting the CD4 Viral Receptor. Cell Rep. 2017.

33. Huang J, Wang F, Argyris E, Chen K, Liang Z, Tian H, et al. Cellular microRNAs contribute to HIV-1 latency in resting primary CD4+T lymphocytes. Nat Med. 2007.

34. Balasubramaniam M, Pandhare J, Dash C. Are microRNAs important players in HIV-1 infection? An update. Viruses. 2018.

35. Su B, Fu Y, Liu Y, Wu H, Ma P, Zeng W, et al. Potential Application of MicroRNA Profiling to the Diagnosis and Prognosis of HIV-1 Infection. Front Microbiol. 2018.

36. Doare K Le, Holder B, Bassett A, Pannaraj PS. Mother's Milk: A purposeful contribution to the development of the infant microbiota and immunity. Frontiers in Immunology. 2018. 
37. Admyre C, Johansson SM, Qazi KR, Filén J-J, Lahesmaa R, Norman M, et al. Exosomes with immune modulatory features are present in human breast milk. J Immunol. 2007.

38. Liao Q, Wang J, Pei Z, Xu J, Zhang X. Identification of miRNA-mRNA crosstalk in CD4+ T cells during HIV-1 infection by integrating transcriptome analyses. J Transl Med. 2017.

39. Detsika MG, Psarris A, Paraskevis D. MicroRNAs and HIV latency: A complex and promising relationship. AIDS Reviews. 2012.

40. Sung TL, Rice AP. miR-198 inhibits HIV-1 gene expression and replication in monocytes and its mechanism of action appears to involve repression of cyclin T1. PLoS Pathog. 2009.

41. Asahchop EL, Akinwumi SM, Branton WG, Fujiwara E, Gill MJ, Power C. Plasma microRNA profiling predicts HIV-associated neurocognitive disorder. AIDS. 2016.

42. Hariharan M, Scaria V, Pillai B, Brahmachari SK. Targets for human encoded mircoRNAs in HIV genes. Biochem Biophys Res Commun. 2005.

43. Shen CJ, Jia YH, Tian RR, Ding M, Zhang C, Wang JH. Translation of Pur-a is targeted by cellular miRNAs to modulate the differentiation-dependent susceptibility of monocytes to HIV-1 infection. FASEB J. 2012.

44. Xu P, Zhu Z, Huan X, Shi Z, Zhou M, Cui L, et al. MicroRNA profiling in plasma of HIV-1 infected patients: potential markers of infection and immune status. J Public Heal Emerg. 2017.

45. Chatterjee A, Leichter AL, Fan V, Tsai P, Purcell R V., Sullivan MJ, et al. A cross comparison of technologies for the detection of microRNAs in clinical FFPE samples of hepatoblastoma patients. Sci Rep. 2015.

46. Farhana L, Dawson MI, Murshed F, Das JK, Rishi AK, Fontana JA. Upregulation of miR-150* and miR-630 Induces Apoptosis in Pancreatic Cancer Cells by Targeting IGF-1R. PLoS One. 2013.

47. Cao JX, Lu Y, Qi JJ, An GS, Mao ZB, Jia HT, et al. MiR-630 inhibits proliferation by targeting CDC7 kinase, but maintains the apoptotic balance by targeting multiple modulators in human lung cancer A549 cells. Cell Death Dis. 2014.

48. Chepenik LG, Tretiakova AP, Krachmarov CP, Johnson EM, Khalili K. The single-stranded DNA binding protein, Pur-a, binds HIV-1 TAR RNA and activates HIV-1 transcription. Gene. 1998.

49. Gallia GL, Darbinian N, Tretiakova AP, Ansari SA, Rappaport J, Brady JN, et al. Association of HIV-1 Tat with the cellular protein, Pur-alpha, is mediated by RNA. Proc Natl Acad Sci. 1999.

50. Swaminathan G, Navas-Martín S, Martín-García J. MicroRNAs and HIV-1 infection: Antiviral activities and beyond. Journal of Molecular Biology. 2014.

51. Cacho NT, Lawrence RM. Innate immunity and breast milk. Frontiers in Immunology. 2017.

52. Ballard O, Morrow AL. Human Milk Composition. Nutrients and Bioactive Factors. Pediatric Clinics of North America. 2013.

53. Ruiz L, Espinosa-Martos I, García-Carral C, Manzano S, McGuire MK, Meehan CL, et al. What's normal? Immune profiling of human milk from healthy women living in different geographical and socioeconomic settings. Front Immunol. 2017. 
54. Andreas NJ, Kampmann B, Mehring Le-Doare K. Human breast milk: A review on its composition and bioactivity. Early Human Development. 2015.

55. B. L-P, J.A. S, S. M, E. M-O, D.C. W, B.A. R, et al. Breast milk cellular HIV-specific interferon gamma responses are associated with protection from peripartum HIV transmission. AIDS. 2012.

56. Moriuchi M, Moriuchi H. Cell-Type-Dependent Effect of Transforming Growth Factor , a Major Cytokine in Breast Milk, on Human Immunodeficiency Virus Type 1 Infection of Mammary Epithelial MCF-7 Cells or Macrophages. J Virol. 2004.

57. Satomi M, Shimizu M, Shinya E, Watari E, Owaki A, Hidaka C, et al. Transmission of macrophage-tropic HIV-1 by breast-milk macrophages via DC-SIGN. J Infect Dis. 2005.

58. Derynck R, Zhang YE. Smad-dependent and Smad-independent pathways in TGF- $\beta$ family signalling. Nature. 2003.

59. Gatignol A, Buckler-White A, Berkhout BEN, Jeang KT. Characterization of a human TAR RNA-binding protein that activates the HIV-1 LTR. Science (80-). 1991.

60. Ong C, Thorpe J, Gorry P, Bannwarth S, Jaworowski A, Howard JL. Low TRBP levels support an innate human immunodeficiency virus type 1 resistance in astrocytes by enhancing the PKR antiviral response. J Virol. 2005.

61. Dorin D, Bonnet MC, Bannwarth S, Gatignol A, Meurs EF, Vaquero C. The TAR RNA-binding protein, TRBP, stimulates the expression of TAR-containing RNAs in vitro and in vivo independently of its ability to inhibit the dsRNA-dependent kinase PKR. J Biol Chem. 2003.

62. Modai S, Farberov L, Herzig E, Isakov O, Hizi A, Shomron N. HIV-1 infection increases microRNAs that inhibit Dicer1, HRB and HIV-EP2, thereby reducing viral replication. PLoS One. 2019.

63. Heaton RK, Clifford DB, Franklin DR, Woods SP, Ake C, Vaida F, et al. HIV-associated neurocognitive disorders persist in the era of potent antiretroviral therapy: Charter Study. Neurology. 2010.

64. Karginov F V., Hannon GJ. Remodeling of Ago2-mRNA interactions upon cellular stress reflects miRNA complementarity and correlates with altered translation rates. Genes Dev. 2013.

65. Grosswendt S, Filipchyk A, Manzano M, Klironomos F, Schilling M, Herzog M, et al. Unambiguous Identification of miRNA: Target site interactions by different types of ligation reactions. Mol Cell. 2014.

66. Huang Y, Chuang A, Hao H, Talbot C, Sen T, Trink B, et al. Phospho- $\triangle N p 63 a$ is a key regulator of the cisplatin-induced microRNAome in cancer cells. Cell Death Differ. 2011.

67. Xue Y, Ouyang K, Huang J, Zhou Y, Ouyang H, Li H, et al. Direct conversion of fibroblasts to neurons by reprogramming PTB-regulated MicroRNA circuits. Cell. 2013.

68. Gottwein E, Corcoran DL, Mukherjee N, Skalsky RL, Hafner M, Nusbaum JD, et al. Viral microRNA targetome of KSHV-Infected primary effusion lymphoma cell lines. Cell Host Microbe. 2011.

69. Whisnant AW, Bogerd HP, Flores O, Ho P, Powers JG, Sharova N, et al. In-depth analysis of the interaction of HIV-1 with cellular microRNA biogenesis and effector mechanisms. MBio. 2013.

70. Braconi C, Huang N, Patel T. Microrna-dependent regulation of DNA methyltransferase-1 and tumor suppressor gene expression by interleukin-6 in human malignant cholangiocytes. Hepatology. 2010. 
71. Balakrishnan I, Yang X, Brown J, Ramakrishnan A, Torok-Storb B, Kabos P, et al. Genome-wide analysis of miRNA-mRNA interactions in marrow stromal cells. Stem Cells. 2014.

72. Chandran PA, Keller A, Weinmann L, Adel Seida A, Braun M, Andreev K, et al. The TGF- $\beta$-inducible miR23a cluster attenuates IFN- levels and antigen-specific cytotoxicity in human CD8+ T cells. J Leukoc Biol. 2014.

73. Skalsky RL, Corcoran DL, Gottwein E, Frank CL, Kang D, Hafner M, et al. The viral and cellular microRNA targetome in lymphoblastoid cell lines. PLoS Pathog. 2012.

74. Zhu H, Wu H, Liu X, Li B, Chen Y, Ren X, et al. Regulation of autophagy by a beclin 1-targeted microRNA, miR-30a, in cancer cells. Autophagy. 2009.

75. Petrocca F, Visone R, Onelli MR, Shah MH, Nicoloso MS, de Martino I, et al. E2F1-Regulated MicroRNAs Impair TGFß-Dependent Cell-Cycle Arrest and Apoptosis in Gastric Cancer. Cancer Cell. 2008.

76. Wu S, Huang S, Ding J, Zhao Y, Liang L, Liu T, et al. Multiple microRNAs modulate p21Cip1/Waf1 expression by directly targeting its $3^{\prime}$ untranslated region. Oncogene. 2010.

77. Furuta M, Kozaki Kl, Tanimoto K, Tanaka S, Arii S, Shimamura T, et al. The Tumor-Suppressive miR-497195 Cluster Targets Multiple Cell-Cycle Regulators in Hepatocellular Carcinoma. PLoS One. 2013.

78. Hyun S, Lee JH, Jin H, Nam JW, Namkoong B, Lee G, et al. Conserved MicroRNA miR-8/miR-200 and Its Target USH/FOG2 Control Growth by Regulating PI3K. Cell. 2009.

79. Yang X, Ni W, Lei K. MiR-200b suppresses cell growth, migration and invasion by targeting notch1 in nasopharyngeal carcinoma. Cell Physiol Biochem. 2013.

80. Fu Y, Liu X, Zhou N, Du L, Sun Y, Zhang X, et al. MicroRNA-200b stimulates tumour growth in TGFBR2null colorectal cancers by negatively regulating p27/kip1. J Cell Physiol. 2014.

\section{Tables}

Table 1: Clinical characteristics of HIV-1-infected and uninfected women 


\begin{tabular}{|c|c|c|c|c|c|c|c|}
\hline Sr. No. & ID No. & Status & Age & HIV Status (Duration till 2017) & ART (Years) & No. of Previous Pregnancies & *Live Babies \\
\hline 1 & $\mathrm{~N}-0379-\mathrm{M}$ & Control & 30 & - & - & 0 & 0 \\
\hline 2 & N-0380-M & Control & 30 & - & - & 3 & 3 \\
\hline 3 & N-0382-M & Control & 26 & - & - & 1 & $0(1)$ \\
\hline 4 & N-0353-M & Control & 30 & - & - & 3 & 3 \\
\hline 5 & N-0356-M & Control & 31 & - & - & 0 & 0 \\
\hline 6 & N-0364-M & Control & 37 & - & - & 7 & 7 \\
\hline 7 & N-0369-M & Control & 31 & - & - & 0 & 0 \\
\hline 8 & N-0371-M & Control & 29 & - & - & 3 & 3 \\
\hline 9 & N-0374-M & Control & 32 & - & - & 2 & $1(1)$ \\
\hline 10 & N-0230-M & HIV-1 & 30 & 2014 (3 years) & 3 & 0 & 0 \\
\hline 11 & N-0231-M & HIV-1 & 35 & 2009 (8 years) & 8 & 9 & $4(5)$ \\
\hline 12 & N-0232-M & HIV-1 & 44 & 2006 (11 years) & 11 & 5 & $3(2)$ \\
\hline 13 & N-0236-M & HIV-1 & 35 & 2011 (6 years) & 6 & 3 & 3 \\
\hline 14 & N-0247-M & HIV-1 & 27 & 2013 (4 years) & 4 & 2 & 2 \\
\hline 15 & N-0248-M & HIV-1 & 30 & 2014 (3 years) & 3 & 3 & 3 \\
\hline 16 & N-0249-M & HIV-1 & 28 & 2011 (6 years) & 6 & 2 & $0(2)$ \\
\hline 17 & N-0251-M & HIV-1 & 29 & 2006 (11 years) & 11 & 5 & $4(1)$ \\
\hline 18 & N-0254-M & HIV-1 & 29 & 2008 (9 years) & 9 & 1 & 1 \\
\hline 19 & N-0130-M & HIV-1 & 31 & 2013 (4 years) & 4 & 2 & 2 \\
\hline 20 & N-0138-M & HIV-1 & 29 & 2011 (6 years) & 6 & 3 & $1(2)$ \\
\hline 21 & N-0140-M & HIV-1 & 39 & 2007 (10 years) & 10 & 5 & 5 \\
\hline 22 & N-0160-M & HIV-1 & 36 & 2014 (3 years) & 3 & 6 & $5(1)$ \\
\hline 23 & N-0164-M & HIV-1 & 24 & 2013 (4 years) & 4 & 2 & $0(2)$ \\
\hline 24 & N-0178-M & HIV-1 & 31 & 2007 (10 years) & 10 & 3 & $2(1)$ \\
\hline 25 & N-0181-M & HIV-1 & 28 & 2011 (6 years) & 6 & 1 & 1 \\
\hline 26 & $\mathrm{~N}-0192 \mathrm{M}$ & HIV-1 & 34 & 2008 (9 years) & 9 & 0 & 0 \\
\hline 27 & N-0196-M & HIV-1 & 29 & 2012 (5 years) & 5 & 0 & 0 \\
\hline 28 & N-0207-M & HIV-1 & 31 & 2006 (11 years) & 11 & 7 & $5(2)$ \\
\hline 29 & N-0211-M & HIV-1 & 35 & 2008 (9 years) & 9 & 3 & $2(1)$ \\
\hline 30 & N-0222-M & HIV-1 & 29 & 2010 (7 years) & 7 & 0 & 0 \\
\hline 31 & N-0226-M & HIV-1 & 30 & 2009 (8 years) & 8 & 2 & 2 \\
\hline 32 & N-0233-M & HIV-1 & 34 & 2006 (11 years) & 11 & 4 & 4 \\
\hline 33 & N-0234-M & HIV-1 & 26 & 2014 (3 years) & 3 & 0 & 0 \\
\hline 34 & N-0238-M & HIV-1 & 30 & 2014 (3 years) & 3 & 7 & $5(2)$ \\
\hline 35 & N-0239-M & HIV-1 & 32 & 2008 (8 years) & 8 & 4 & $2(2)$ \\
\hline 36 & $\mathrm{~N}-0240-\mathrm{M}$ & HIV-1 & 28 & 2002 (15 years) & 15 & 2 & $1(1)$ \\
\hline
\end{tabular}

*Number of deceased are shown in parenthesis

Table 2: Differentially expressed human milk exosomal miRNAs in HIV-1 infected women 


\begin{tabular}{|c|c|c|c|c|c|c|}
\hline s̀r. No. & miRNA ID & Log Fold Change & Fold Change & p-value & Adj. p-value & Regulation \\
\hline L & hsa-miR-320e & 3.06611 & 8.375124 & 2.57E-03 & 0.124605 & UP \\
\hline 2 & hsa-miR-630 & 2.979453 & 7.886873 & 2.03E-05 & 0.005408 & UP \\
\hline 3 & hsa-miR-148a-3p & 1.896117 & 3.7221 & $5.14 \mathrm{E}-04$ & 0.068612 & UP \\
\hline 1 & hsa-miR-23a-3p & 1.003622 & 2.005028 & $8.26 \mathrm{E}-03$ & 0.207538 & UP \\
\hline j & hsa-miR-378g & 0.866517 & 1.823256 & $1.24 \mathrm{E}-03$ & 0.110628 & UP \\
\hline$j$ & hsa-miR-30a-5p & 0.834559 & 1.783312 & $1.96 \mathrm{E}-02$ & 0.308391 & UP \\
\hline 7 & hsa-miR-93-5p & 0.693353 & 1.617037 & 1.68E-02 & 0.279933 & UP \\
\hline 3 & hsa-miR-497-5p & 0.682571 & 1.604997 & $1.02 \mathrm{E}-02$ & 0.207538 & UP \\
\hline 3 & hsa-miR-200b-3p & 0.580053 & 1.494904 & $2.82 \mathrm{E}-02$ & 0.350687 & UP \\
\hline 10 & hsa-miR-16-5p & 0.555462 & 1.469639 & $5.44 \mathrm{E}-02$ & 0.386215 & UP \\
\hline L1 & hsa-miR-422a & -0.50323 & 1.41738 & 3.84E-02 & 0.381103 & DOWN \\
\hline 12 & hsa-miR-644a & -0.47998 & 1.394723 & $2.08 \mathrm{E}-03$ & 0.124605 & DOWN \\
\hline 13 & hsa-miR-200a-3p & 0.445082 & 1.361391 & 5.88E-02 & 0.386215 & UP \\
\hline 14 & hsa-miR-520a-5p & -0.40659 & 1.325552 & $3.27 \mathrm{E}-03$ & 0.124605 & DOWN \\
\hline$\overline{15}$ & hsa-miR-506-5p & -0.39559 & 1.315479 & $5.92 \mathrm{E}-03$ & 0.197641 & DOWN \\
\hline 16 & hsa-miR-1262 & 0.386293 & 1.307031 & 1.13E-02 & 0.207538 & UP \\
\hline 17 & hsa-miR-4516 & 0.386214 & 1.306959 & $1.10 \mathrm{E}-02$ & 0.207538 & UP \\
\hline 18 & hsa-miR-1257 & -0.38522 & 1.306057 & 3.23E-03 & 0.124605 & DOWN \\
\hline 19 & hsa-miR-1253 & -0.38439 & 1.305306 & 2.43E-02 & 0.350687 & DOWN \\
\hline
\end{tabular}

Table 3: Tarbase v8.0 based target genes of the top ten differentially expressed human milk exosomal miRNAs in HIV-1 infected women 


\begin{tabular}{|c|c|c|c|}
\hline $\begin{array}{l}\text { niRNA } \\
\text { ID }\end{array}$ & $\begin{array}{c}\text { No. of } \\
\text { Interactions }\end{array}$ & $\begin{array}{l}\text { *Target Genes } \\
\text { (Gene Symbols) }\end{array}$ & Reference \\
\hline $\begin{array}{l}\text { ssa- } \\
\text { niR- } \\
20 e\end{array}$ & 327 & $\begin{array}{l}\text { CDK6, MEGEA5, IGF2BP3, BTG2, WASF2, MINK1, SFPQ, PTBP1, BLMH, JUN, NUCKS1, CDK16, } \\
\text { DYRK2, RTN4, CAND1, CLN6, MARCK5, RPL32, OAZ1, CSNK1A1, BAMBI, IRF3, DCAF7, ITGAV, } \\
\text { BCL2L11, HNRNPU, DHX33, RNF10, UBE3C, WDR6, HERC1, NSD3 }\end{array}$ & {$[64,65]$} \\
\hline $\begin{array}{l}\text { isa- } \\
\text { niR- } \\
\text { i30 }\end{array}$ & 3 & BCL2, BCL2L2, YAP1 & {$[66]$} \\
\hline $\begin{array}{l}\text { isa- } \\
\text { niR- } \\
48 a- \\
\text { p }\end{array}$ & 1481 & $\begin{array}{l}\text { DNMT1, IGF1R, IRS1, ITGB8, BCL2L11, DCAF7, RAB1B, USP28, CDKN1B, ZNF460, TNRC6A, } \\
\text { JAR1D2, CDK1, ATP5E, GAND1, PRNP, PBXIP1, CAND1, PBXIP1, RAB1B, CCN1, NR1D2, DCAF7, } \\
\text { USP28 }\end{array}$ & {$[67-71]$} \\
\hline $\begin{array}{l}\text { ssa- } \\
\text { niR- } \\
\text { :3a-3p }\end{array}$ & 1744 & $\begin{array}{l}\text { ZNF91, CXCL12, LAMP1, IFNG, CDK17, CDK1, HDAC7, TCF20, MTMR2, TOP2B, VACN, TRIB1, } \\
\text { UBL3, FUT9, TSNAX, TJP2, AHNAK, TNRC6A, ZNF107, CBX5, CREBZF, SESN3, UFM1, EIF2A, } \\
\text { STX12 }\end{array}$ & 更 \\
\hline $\begin{array}{l}\text { sa- } \\
\text { niR- } \\
\text { i78g }\end{array}$ & 123 & $\begin{array}{l}\text { TAOK1, PPP1R37, VE2F1, SP4, CBLC1, MBP, PSMD8, PABPC3, BLOC1S6, WDR5, SMAD2, FKBP4, } \\
\text { PIAS1, KCTD20, PSMD8, TNRC6C, PAPOLA, CREBBP, CDH1, TARBP2, HIVEP3 }\end{array}$ & {$[68,73]$} \\
\hline $\begin{array}{l}\text { ssa- } \\
\text { niR- } \\
0 a-5 p\end{array}$ & 2808 & $\begin{array}{l}\text { TNRC6A, DDIT4, RHOB, E2F7, BRWD1, NDEL1, DHX36, FBXO45, RPA2, XRN1, SOCS1, PLA2G12A, } \\
\text { IFNGR2, DCAF12, ATG12, ERLIN1, NOTCH1, BECN1P1, DDAH1, MAST4, AGO2, SOX4, IPO4, } \\
\text { SLC20A1, RNF139, VAMP3, DDIT4, RHOB, ANKRA2, LCOR, ZBTB18, NDEL1, XPO1, XRN1, PFN2, } \\
\text { SRSF7 }\end{array}$ & $\begin{array}{l}{[67,68,71,} \\
74]\end{array}$ \\
\hline $\begin{array}{l}\text { sa- } \\
\text { niR- } \\
\text { i3-5p }\end{array}$ & 2227 & $\begin{array}{l}\text { CDKN1A, CSKN1A1, CLIP1, ANKIB1, BACH1, CLTC, ULK1, DZAPAP2, CCND1, PELI1, MOB1A, E2F1, } \\
\text { PIK3R1, RAB22A, IRF9, TNKS2, MAPK1, TXN, TMEM138, USP31, RRM2, MKNK2, PFN2, PURA, } \\
\text { ADAM9, ZNFX1, RUFY2, TXNIP, SEMA7A, JAK1, CNOT4, WEE1, BNIP2, IPO7, RAB5B }\end{array}$ & $\begin{array}{l}{[68,69,73,} \\
75,76]\end{array}$ \\
\hline $\begin{array}{l}\text { ssa- } \\
\text { niR- } \\
: 97-5 p\end{array}$ & 1590 & $\begin{array}{l}\text { CCND1, CCNE1, E2F3, CDK6, ACTB, CCND3, CDk4, CDC25A, BTRC, TXNIP, FBXW7, ABI2, BTG2, } \\
\text { WEE1, HSPA1B, ARL2, CSDE1, CCND1, CDCA4, BTG2, ATG9A, PDCD4, SESN3, SMAD2, NOTCH2, } \\
\text { IGF1R, DDX6, MAPK8, PURA, TLK1, TACC1, HIPK2, BCL2L2 }\end{array}$ & {$[71,73,77]$} \\
\hline
\end{tabular}




\begin{tabular}{|c|c|c|c|}
\hline $\begin{array}{l}\text { sa- } \\
\text { niR- } \\
\text { :00b- } \\
\text { ip }\end{array}$ & 1905 & $\begin{array}{l}\text { TCF7L1, ERBB21P, VAC14, RASSF2, NOTCH1, CDKN1B, AKAP11, CAB39, ANKRD42, ETS1, KRAS, } \\
\text { YES1, TBP, XIAP, ZEB1, BCL2, NDFIP2, WEE1, JUN, RND3, ETS1, GLS, KDR, TOB1, NRBP1, FLT1, } \\
\text { SMURF2, IRF9 }\end{array}$ & {$[73,78-80]$} \\
\hline $\begin{array}{l}\text { sa- } \\
\text { niR- } \\
6-5 p\end{array}$ & 7687 & (1) & (1) \\
\hline
\end{tabular}

*Some of the target genes out of total are shown here in the table

\section{Figures}




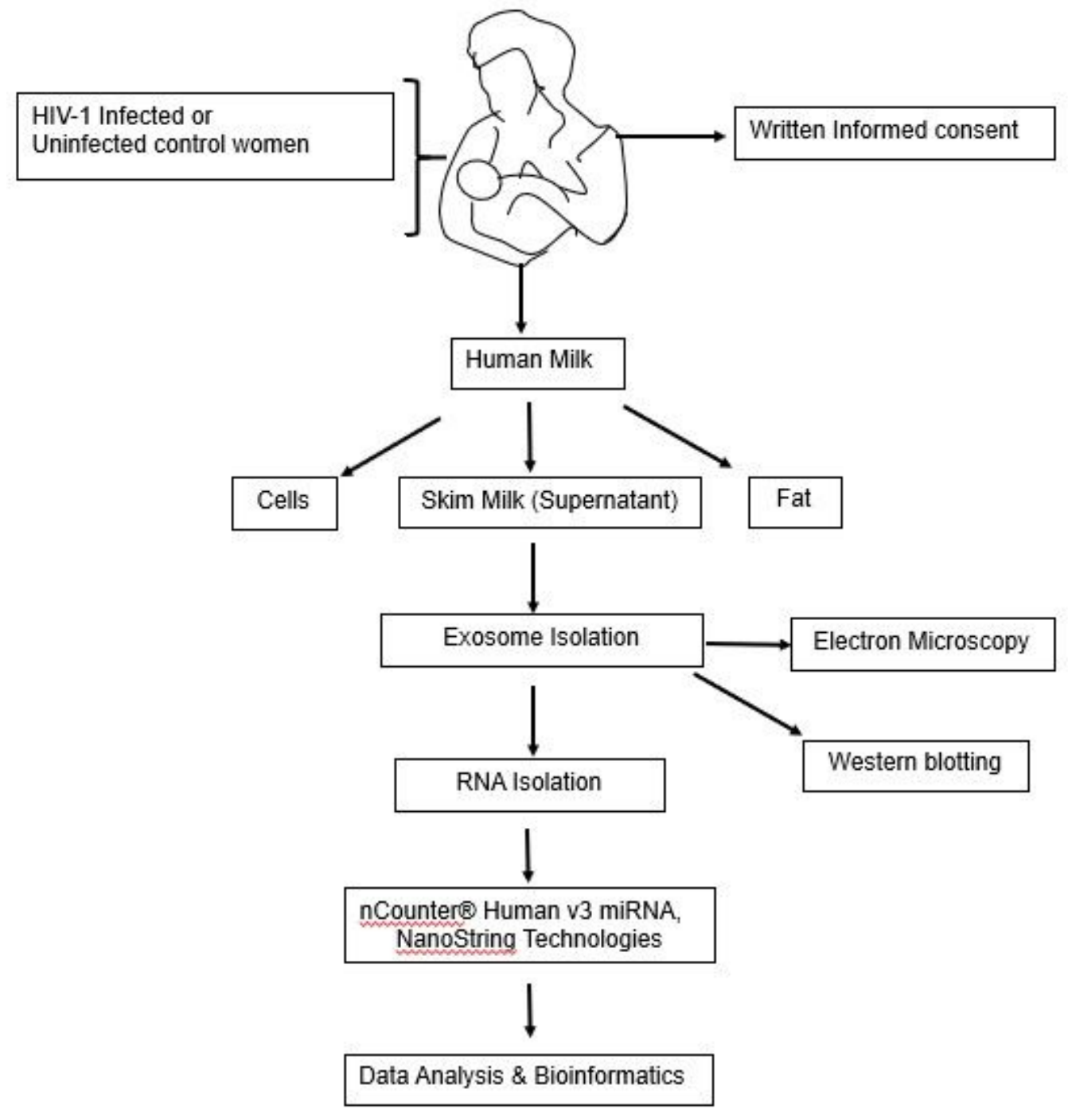

\section{Figure 1}

Human Milk Exosome characterization and RNA isolation. A). Transmission electron micrograph of human milk exosomes demonstrates small vesicles with sizes ranging from 30-100 nm in diameter (Magnification: 300,000X; Scale bar $100 \mathrm{~nm}$ ) (B) Western blotting for exosome-associated marker protein CD81. 10, 20, and $40 \mathrm{\mu g}$ of proteins from either freshly isolated or human milk exosomes kept at room temperature (RT) for 2 days were loaded (C) Electropherogram and (D) gel images of representative RNAs extracted from human milk exosomes run on Agilent 2100 Bioanalyzer. Lanes 1-9 correspond to 37-45 samples; L: Ladder 
A

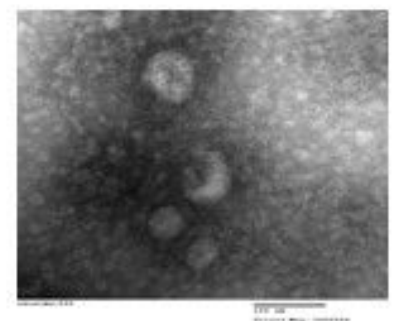

$\min =\ldots$

\section{B}

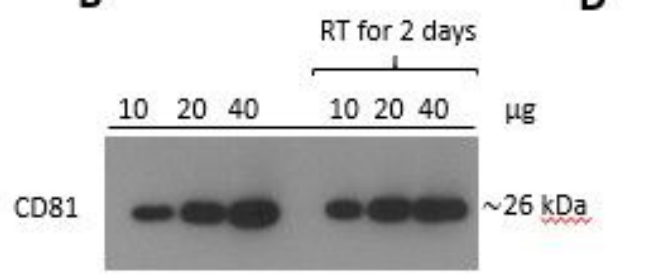

C

D
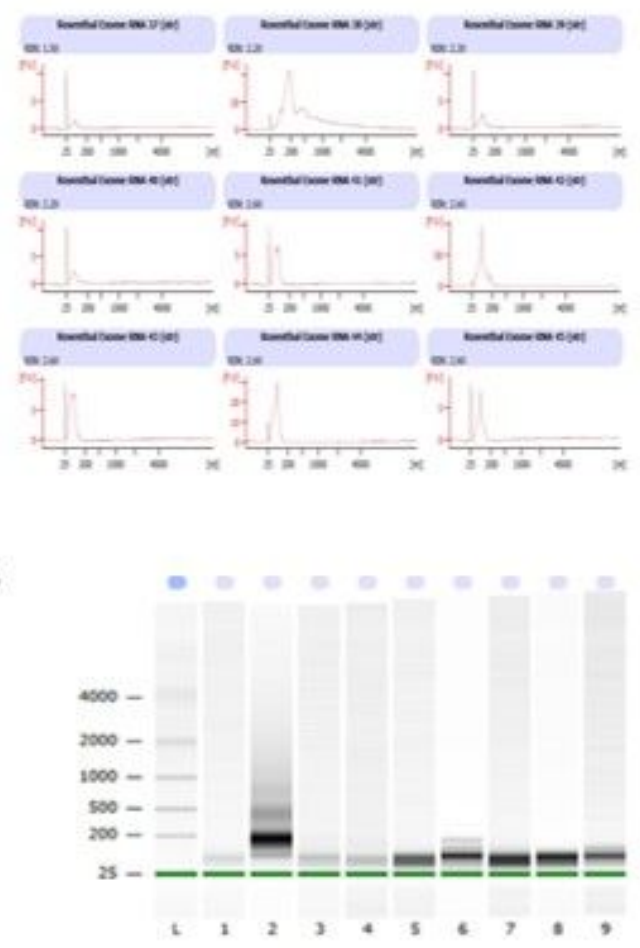

\section{Figure 2}

Human Milk Exosome characterization and RNA isolation. A). Transmission electron micrograph of human milk exosomes demonstrates small vesicles with sizes ranging from 30-100 nm in diameter (Magnification: 300,000X; Scale bar $100 \mathrm{~nm}$ ) (B) Western blotting for exosome-associated marker protein CD81. 10, 20, and $40 \mu \mathrm{g}$ of proteins from either freshly isolated or human milk exosomes kept at room temperature (RT) for 2 days were loaded (C) Electropherogram and (D) gel images of representative RNAs extracted from human milk exosomes run on Agilent 2100 Bioanalyzer. Lanes 1-9 correspond to 37-45 samples; L: Ladder 


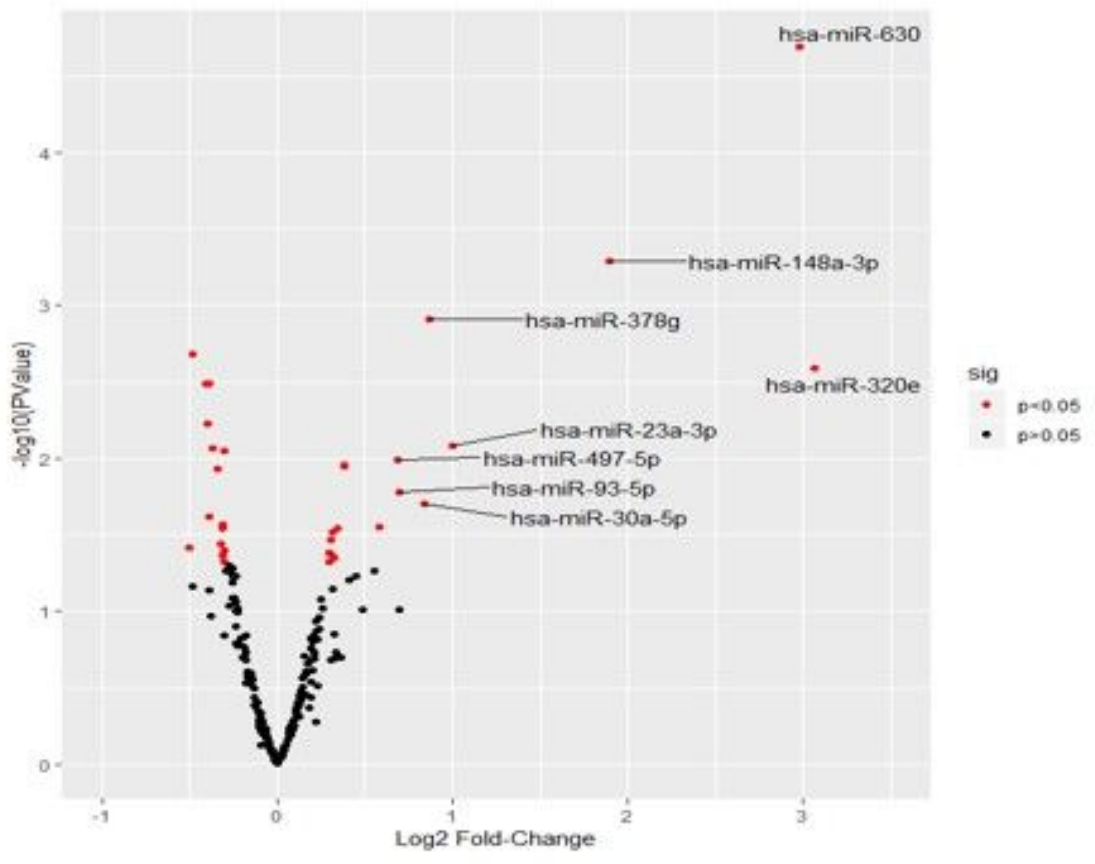

\section{Figure 3}

Differential expression of human milk exosome miRNAs in HIV-1 infected women. The differential expression profile of human milk exosomal miRNAs is shown as a volcano plot which demonstrates fold change versus significance $(p<0.05)$ to exhibit differences in the miRNA expression between HIV- 1 infected and uninfected control women. The $\mathrm{X}$-axis of the plot shows log-base two-fold change whereas $\mathrm{Y}$-axis shows the log $p$-value. Red color indicates the level of significance $(p<0.05)$. 

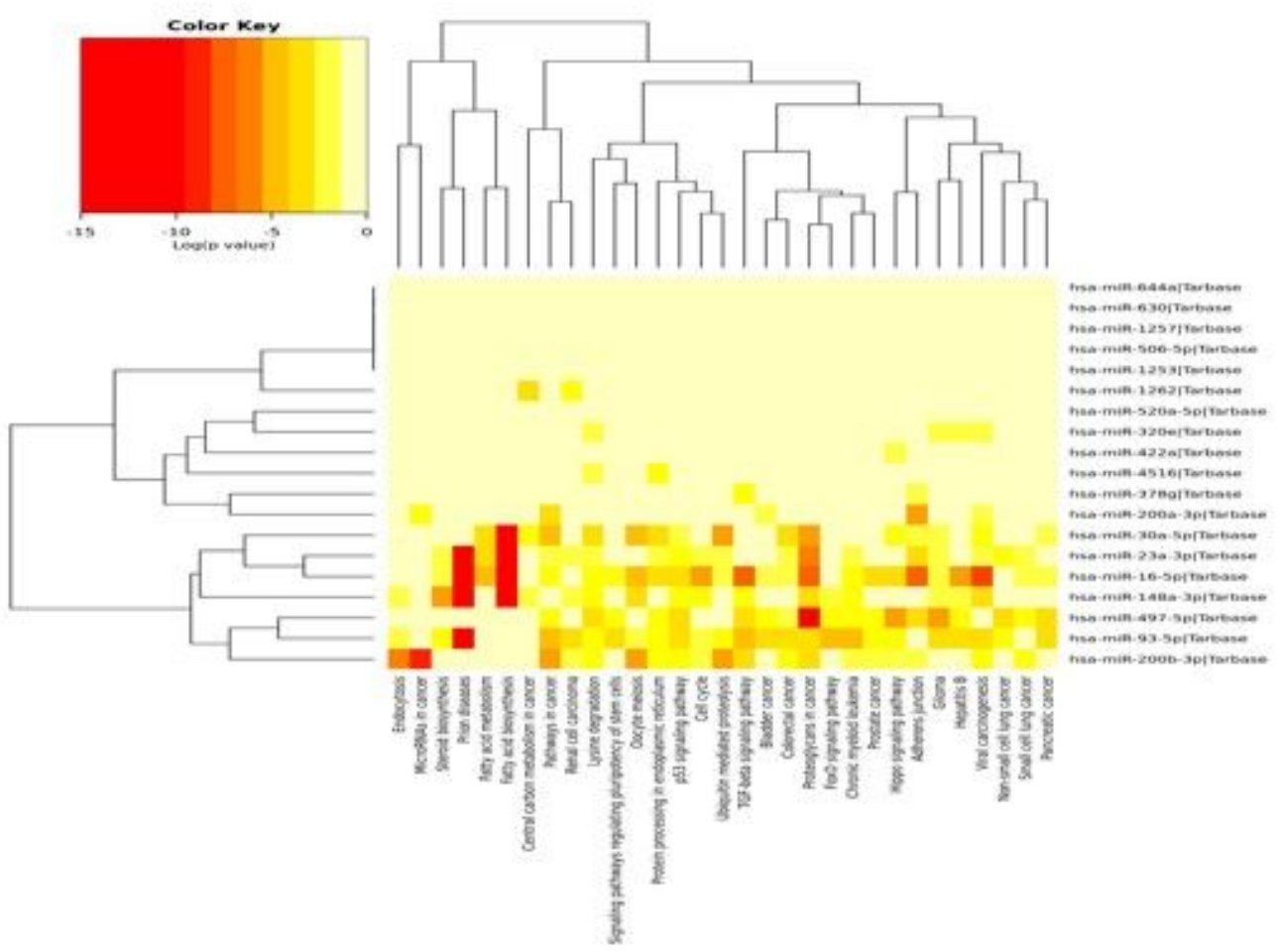

\section{Figure 4}

KEGG Pathway analysis of differentially expressed human milk exosome miRNAs. Differentially expressed exosomal miRNAs in HIV-1 infected human milk regulate multiple cellular pathways. Depicted here in the heatmap, significant pathways generated by DIANA-miRPath v3.0 software using Tarbase database are shown on the X-axis whereas miRNAs are shown on the $Y$-axis. The color code represents the log ( $p$-value), with the most significant predicted miRNA-pathway interactions in red. 

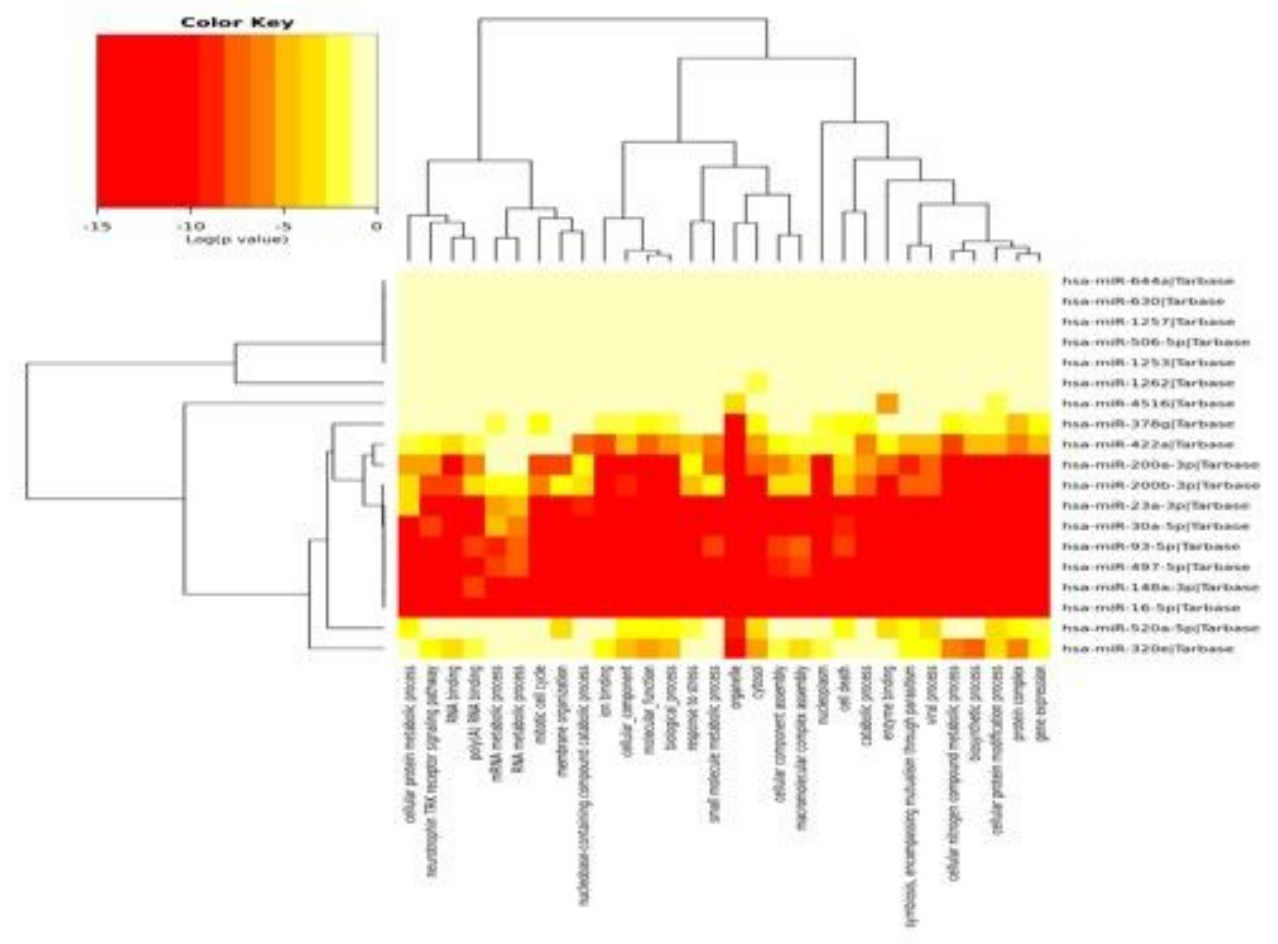

\section{Figure 5}

Gene Ontology Analysis of differentially expressed human milk exosome miRNAs. Gene Ontology of differentially expressed exosomal miRNAs in HIV-1 infected human milk is shown as heatmap which was created by DIANA-miRPath v3.0 software using Tarbase database. The heatmap enables similar miRNAs to cluster together in the same GO term. The color code represents the log (p-value), with the most significant GO term in red. 


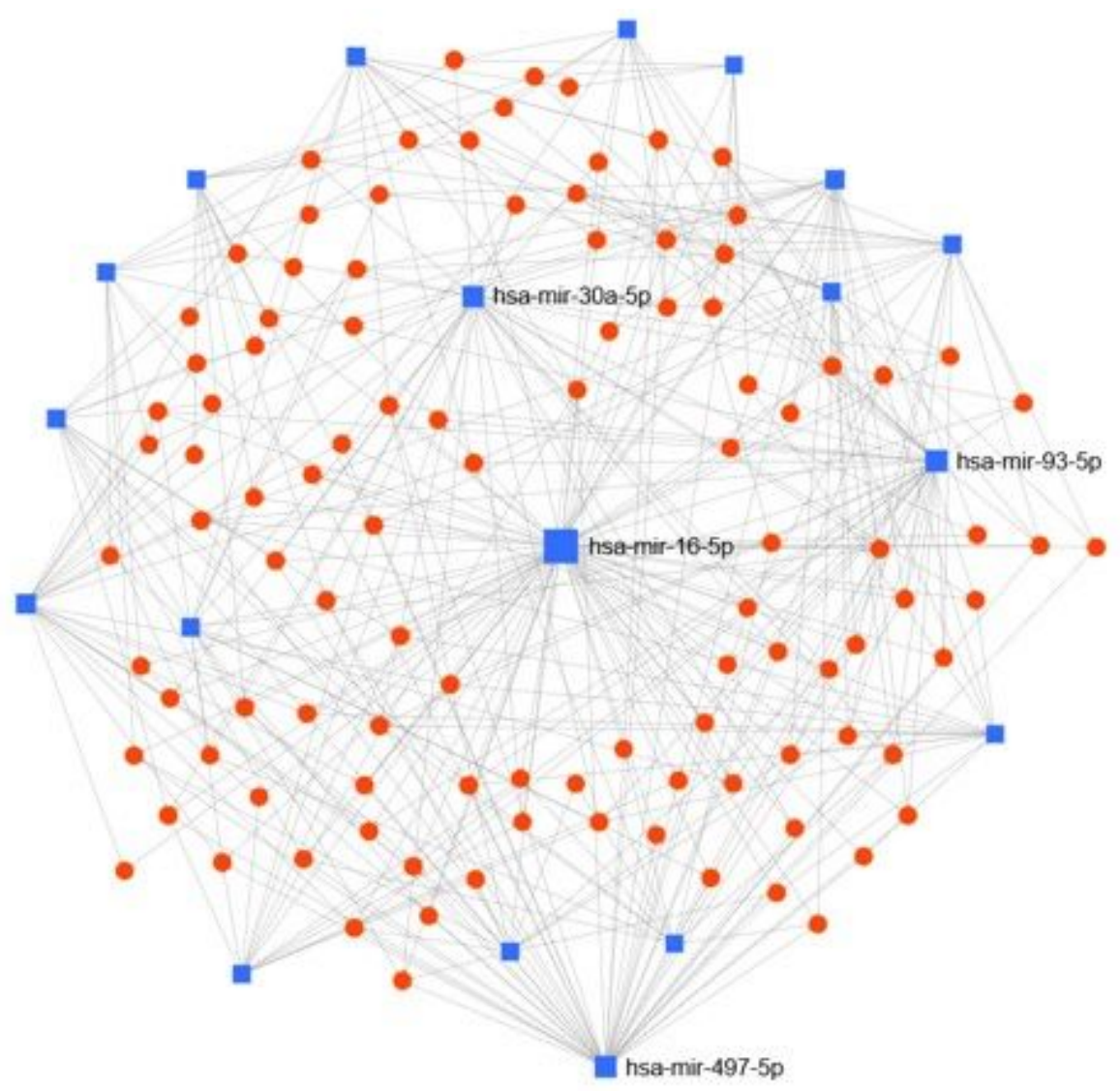

\section{Figure 6}

Network analysis of differentially expressed miRNAs and their target genes in HIV-1 infected human milk. Network display showing differentially expressed miRNAs (Fold change 1.3; $p<0.05$ ) and their target genes in HIV-1 infected human milk. Cluster hubs shown in blue squares indicate miRNAs whereas red circles depict their target genes. 

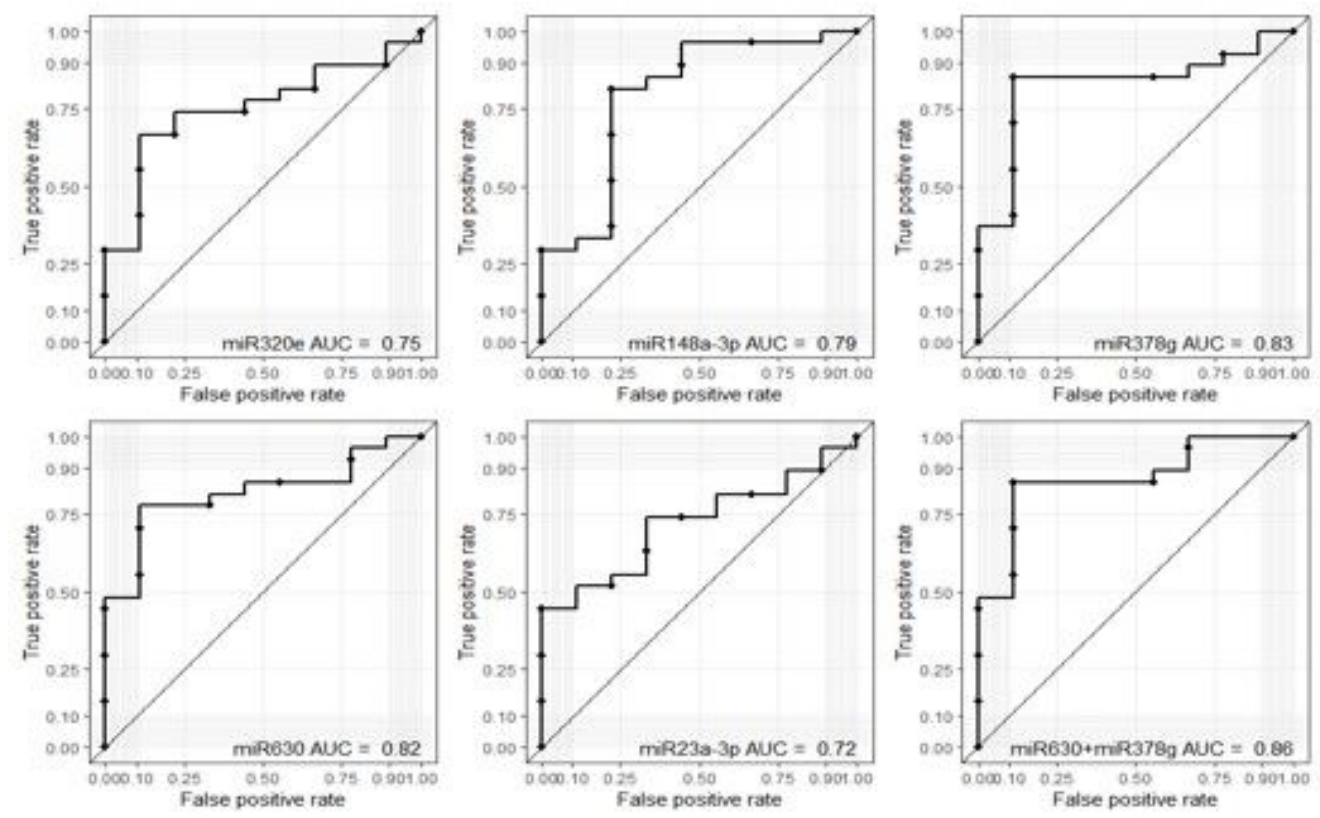

\section{Figure 7}

ROC curve analysis of human milk exosome miRNAs. ROC curves for the individual top five (miRNA-320e, miRNA-148a-3p; miRNA-378g, miRNA-630 and miRNA-23a-3p) or combined miRNAs (miRNA-630 and miRNA-378g) for discriminating HIV-1 infected women from healthy controls. ROC: receiver operating characteristic; AUC, area under the ROC curve. 


\section{A}

Position 382-388 of TARBP2 $3^{\prime}$ UTR $5^{\prime}$......CACAGAGCCUCAGCCAGCCCAGG ....... $3^{\prime}$

hsa-miR-378g

3'........GAAGACUGAGGUUCGGGUCA......5'

B

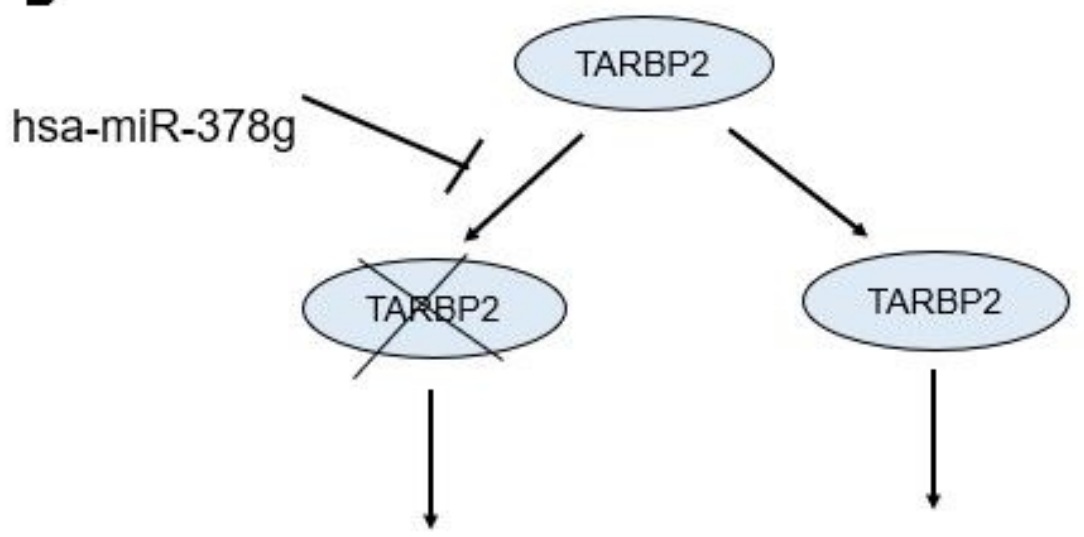

No HIV-1 LTR binding

No Transactivation

|

HIV-1 Replication
Binding to HIV-1 LTR \&

Transactivation

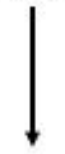

HIV-1 Replication

\section{Figure 8}

Hypothetical model showing miR-378g mediated TARBP2 depletion and inhibition of HIV-1 replication. A). Target nucleotide sequence of 3' UTR of Human TARBP2 (ENST00000552857.1) recognized by miR-378g as confidently annotated by TargetScan v7.2. Predicted consequential pairing of target region is shown in the top and miRNA-378g sequence in the bottom. B). TARBP2, a cellular protein originally identified as a binding partner of HIV-1 LTR (transactivation response element found at both $5^{\prime}$ and $3^{\prime}$ ) and is well known to enhance HIV-1 expression and virus production, once depleted by host cellular miR-378g would presumably lower the HIV-1 expression and virus production [30].

\section{Supplementary Files}

This is a list of supplementary files associated with this preprint. Click to download.

- SupplTable1.docx 